\title{
Axotomy-Induced Changes in the Chemical Coding Pattern of Colon Projecting Calbindin-Positive Neurons in the Inferior Mesenteric Ganglia of the Pig
}

\author{
Joanna Wojtkiewicz • Maciej Równiak • \\ Robert Crayton • Slawomir Gonkowski • Anna Robak • \\ Michal Zalecki • Mariusz Majewski • \\ Lars Klimaschewski
}

Received: 8 January 2013 /Accepted: 18 March 2013 /Published online: 2 April 2013

(C) The Author(s) 2013. This article is published with open access at Springerlink.com

\begin{abstract}
The present study examines the response of colon-projecting neurons localized in the inferior mesenteric ganglia (IMG) to axotomy in the pig animal model. In all animals $(n=8)$, a median laparotomy was performed under anesthesia and the retrograde tracer Fast Blue was injected into the descending colon wall. In experimental animals $(n=$ 4 ), the descending colon was exposed and the bilateral
\end{abstract}

\section{J. Wojtkiewicz $(\bowtie)$}

Department of Neurology and Neurosurgery,

Stem Cell Research Laboratory, Faculty of Medical Sciences,

University of Warmia and Mazury, Warszawska 30,

10-082 Olsztyn, Poland

e-mail: Joanna.Wojtkiewicz@uwm.edu.pl

M. Równiak · A. Robak

Department of Comparative Anatomy, Faculty of Biology,

University of Warmia and Mazury, Olsztyn, Poland

R. Crayton

Department and Clinic of Urology, Faculty of Medical Sciences,

Medical University of Warsaw, Warsaw, Poland

S. Gonkowski

Department of Clinical Physiology, Faculty of Veterinary

Medicine, University of Warmia and Mazury, Olsztyn, Poland

\section{Zalecki}

Department of Animal Anatomy, Faculty of Veterinary Medicine, University of Warmia and Mazury, Olsztyn, Poland

\section{Majewski}

Department of Human Physiology, Faculty of Medical Sciences, University of Warmia and Mazury, Olsztyn, Poland

\section{Klimaschewski}

Department of Anatomy, Histology and Embryology, Division of Neuroanatomy, Medical University of Innsbruck, Innsbruck, Austria caudal colonic nerves were identified and severed. All animals were euthanized and the inferior mesenteric ganglia were harvested and processed for double-labeling immunofluorescence for calbindin-D28k (CB) in combination with either tyrosine hydroxylase (TH), neuropeptide Y (NPY), somatostatin (SOM), vasoactive intestinal polypeptide (VIP), nitric oxide synthase (NOS), Leu-enkephalin (LENK), substance P, vesicular acetylcholine transporter, or galanin. Immunohistochemistry revealed significant changes in the chemical coding pattern of injured inferior mesenteric ganglion neurons. In control animals, Fast Bluepositive neurons were immunoreactive to TH, NPY, SOM, VIP, NOS, LENK, and CB. In the experimental group, the numbers of TH-, NPY-, and SOM-expressing neurons were reduced, whereas the number of neurons immunoreactive to LENK was increased. Our data indicate that the colonprojecting neurons of the porcine IMG react to the axotomy in a similar, but not an identical manner in a comparison to other species, especially rodents. Further studies are needed to elucidate the detailed factors/mechanisms involved in the response to nerve injury.

Keywords Axotomy · Neuropeptides · Colon-supplying neurons $\cdot$ Inferior mesenteric ganglion $\cdot$ Pig

\section{Introduction}

The blood flow, secretions, and motility of the gastrointestinal tract (GIT) are controlled by the enteric nervous system. It is composed of both the intramural plexuses and extrinsic autonomic neurons that are located in the prevertebral and paravertebral ganglia (Brown and 
Timmermans 2004; Furness 2012; Luckensmeyer and Keast 1995). Previous investigations have shown that in the case of the colon, the main source of extrinsic innervation is located within inferior mesenteric ganglion (IMG) (Dalsgaard and Elfvin 1982; Li and Masuko 2001). Moreover, both enteric neurons and extrinsic innervation of the gastrointestinal tract are able to undergo structural, functional, and chemical changes as a result of adaptive or reparative processes in response to different physiological and pathological stimuli, such as development, aging, diet, or intestinal and extra-intestinal diseases (Balemba et al. 1998; Ekblad et al. 1998; Phillips and Powley 2007).

One of the factors that induces a sequence of morphological, biochemical, and electrophysiological changes both in affected neurons and neighboring nonneuronal cells is axotomy (Sun and Zigmond 1996; Yamada et al. 2008). It has been shown that the transection of the axon leads to a decrease of catecholamine biosynthesis and changes in the expression pattern of neuroprotective/neuroregenerative peptides. These include galanin (GAL), nitric oxide synthase (NOS), vasoactive intestinal peptide (VIP), and substance P (SP) (Hyatt-Sachs et al. 1996; Klimaschewski et al. 1996; Reimer and Kanje 1999; Zigmond and Sun 1997; Zigmond 2000). These changes are an example of plasticity in the peripheral nervous system that allows the sympathetic neurons to survive and regenerate after axonal damage (Boeshore et al. 2004; Sun et al. 1996; Zigmond and Sun 1997).

Although a decrease of catecholamine biosynthesis is commonly observed after injury to sympathetic neurons (Skobowiat et al. 2011; Zigmond 2000), the second phenomenon, i.e., the induction or overexpression of neuroprotective/neuroregenerative peptides in affected neurons seems to be organ dependent as well as species specific (Lindh et al. 1993; Majewski et al. 2002; Olsson et al. 2006; Reimer and Kanje 1999; Skobowiat et al. 2011; Zigmond 1997). For example, in the rat, NOS and VIP expression rates increase in a subpopulation of neurons of the axotomized superior cervical ganglion (Hyatt-Sachs et al. 1996; Klimaschewski et al. 1994, 1996; Mohney et al. 1994), but in the pig, axotomy did not change NOS or VIP synthesis rate in neurons of the porcine inferior mesenteric ganglion (Majewski et al. 2002). On the other hand, axotomy changes the chemical coding of neuronal cells within the enteric nervous system in the descending colon (Gonkowski and Calka 2010, 2012).

Apart from the decrease of catecholamine biosynthesis and the changes in the expression pattern of neuroprotective/neuroregenerative peptides, axotomy also causes a massive influx of calcium into the lesioned neurons (Obal et al. 2006; Wolf et al. 2001). Calcium influx is highly cytotoxic, so resection of the nerve should induce extensive neuronal cell death (LoPachin and Lehning 1997). However, axotomy of the hypoglossal nerve does not induce extensive neuronal cell death in rats (Krebs et al. 1997). A large percentage $(70 \%)$ of these neurons has been shown to survive despite permanent target deprivation (Krebs et al. 1997). One of the mechanisms responsible for this substantial survival rate in rats may be changes in the $\mathrm{Ca}^{2+}$ buffering system. For example, as a reaction to the hypoglossal nerve axotomy, lesioned neurons trigger an increase in calbindin expression which acts as a compensatory $\mathrm{Ca}^{2+}$ buffering system, enabling neurons to maintain $\mathrm{Ca}^{2+}$ homeostasis and the survival after axotomy (Krebs et al. 1997). Calbindin-D28K is an intracellular calcium-binding protein, which acts as $\mathrm{Ca}^{2+}$ buffering system in the cytoplasm (Schwaller et al. 2002; Schwaller 2009). By means of this property, calbindin may protect neurons against large fluctuations in free intracellular $\mathrm{Ca}^{2+}$ and may prevent cell death. Therefore, we designed our experiments to decipher changes induced by caudal colonic nerve axotomy on the chemical coding of postganglionic, sympathetic IMG neurons innervating the colon of the pig by applying Fast Blue tracing, axotomy, and double-labeling immunofluorescence for calbindin-D28k in combination with various other substances. It should be pointed out that axotomy of the neurons supplying the GIT can be associated with the majority of surgical operations on stomach and intestines, but also with the mechanical injuries of abdominal cavity. So the studies on the axotomy-induced changes in the chemical coding of neurons supplying the gastrointestinal tract seem to be of interest, especially in the pig due to its anatomical, histological, and physiological similarities to the human GI tract (Brown and Timmermans 2004). Pigs and humans also have similar immune systems and inflammatory responses (Patterson et al. 2008; Swindle and Smith 2007; Verma et al. 2011). Due to all these similarities, the pig animal model is an optimal model for various human diseases including cardiovascular diseases, obesity, diabetes, as well as injury and repair of tissues (Litten-Brown et al. 2010; Sullivan et al. 2001; Swindle and Smith 2007; Swindle et al. 2012). Therefore, as calbindin-D28k (CB) could play an important role as a calcium ion buffer, especially under pathological conditions, we decided to investigate in detail the eventual changes in the number and chemical phenotypes of colonprojecting and $\mathrm{CB}$-expressing neurons in IMG induced by an axotomy.

\section{Material and Methods}

\section{Study Subjects}

The study was performed on eight immature female pigs of the Large White Polish breed ( 8 weeks old) divided into two groups: control (C group, $n=4$ ) and axotomized animals (AXO group; $n=4$ ). All animals were housed and treated in accordance with rules approved by the ethics committee 
(conforming to the Principles of Laboratory Animal Care, NIH publication no. 86-23, revised 1985). As the present study was designated to provide basic data concerning the chemical phenotypes of IMG neurons both under physio- as well as patophysiological conditions (axotomy), the authors decided to focus on sexually immature female animals in order to exclude any possible influences of reproductive hormones on studied cells as identified in previous studies (Purves-Tyson and Keast 2004; Koszykowska et al. 2011).

\section{Anesthesia and Surgery}

Surgery was performed under fractionated thiobarbital (Thiopenthal, Sandoz, Austria; $20 \mathrm{mg} / \mathrm{kg}$ b.w., i.v.) anesthesia. Prior to administration (30 min) of the main anesthetic, the animals were pretreated with atropine sulfate (Polfa, Poland; $0.04 \mathrm{mg} / \mathrm{kg}$ b.w., s.c.) and azaperone (Stressnil, Janssen Pharmaceutica, Belgium; $2.0 \mathrm{mg} / \mathrm{kg}$ b.w., i.m.). All animals $(n=8)$ were laparotomized and injected with $5 \%$ aqueous solution of the fluorescence retrograde neuronal tracer Fast Blue (FB; Dr. K. Illing GmbH, Gross-Umstadt, Germany) into the wall of the descending colon. A total volume of $40 \mu \mathrm{l}$ of $5 \%$ aqueous dye solution was injected into the exposed descending colon using a Hamilton syringe with a 26-gauge needle. Multiple injections ( $n=40 ; 1 \mu l$ each) were made into the right side of the descending colon wall, using the mesocolon as the bordering mark. Three weeks later, all animals underwent a median laparotomy to expose the descending colon and the bilateral nervi colici caudales (a sole link between the IMG and this bowel segment). In half of the animals, the nerves were transected (AXO group), while in the control group after visualization their continuity was maintained. After 7 days, all animals were reanesthetized and euthanized by an overdose of sodium thiobarbital then perfused transcardially with $4 \%$ buffered paraformaldehyde ( $\mathrm{pH}$ 7.4). Following perfusion, small tissue blocks containing the IMG were collected from all studied animals and postfixed by immersion in the same fixative for $4 \mathrm{~h}$, washed twice in $0.1 \mathrm{M}$ phosphate buffer $\left(\mathrm{pH}=7.4,4{ }^{\circ} \mathrm{C}\right)$, and then stored in $18 \%$ sucrose at $4{ }^{\circ} \mathrm{C}$ until sectioning.

\section{Immunofluorescence Experiments}

Ten-micrometer-thick cryostat sections of IMGs were processed for routine double-immunofluorescence labeling using primary antisera raised in different species and species-specific secondary antibodies (Table 1). All sections were incubated overnight in a humid chamber with a mixture consisting of antibodies directed towards $\mathrm{CB}$ and an antiserum raised against either tyrosine hydroxylase (TH), neuropeptide Y (NPY), somatostatin (SOM), vasoactive intestinal polypeptide (VIP), nitric oxide synthase (NOS), leucine-enkephalin (LENK), SP, vesicular acetylcholine transporter (VAChT), or GAL (Table 1). Sections were then incubated with a mixture of appropriate fluorescein isothiocyanate (FITC)-conjugated secondary antisera and biotinylated goat antirabbit antibodies $(1 \mathrm{~h})$. The latter antibodies were finally visualized by additional incubation of sections with streptavidin-CY3 complex (1 h). After staining, the sections were mounted with carbonate-buffered glycerol $(\mathrm{pH}$ 8.6) and cover slipped. Each step of immunolabeling was followed by rinsing of the sections with PBS $(3 \times 15 \mathrm{~min})$.

\section{Controls}

Standard controls, i.e., preabsorption for the neuropeptide antisera (20 mg of appropriate antigen per $1 \mathrm{ml}$ of corresponding antibody at working dilution), and the omission and replacement of all primary antisera by nonimmune sera or PBS were applied to test both antibody and method specificity. Antigens used for the preabsorption tests were as follows: SOM (code S9129, Sigma, St. Louis, USA), NPY (code PEP-87135, Dianova, Hamburg, Germany), and SP (code S6883, Sigma). Apart from the preabsorption experiments, all primary antibodies were tested on selected porcine brain tissue samples where the studied antigens were previously reported. The secondary antisera were tested by omission and replacement procedures.

\section{Cell Counting and Statistics}

The sections were viewed under an Olympus BX51 fluorescence microscope equipped with a barrier filter for FB and the respective filters for FITC and CY3. Microphotographs were acquired with a CCD camera connected by a PC equipped with Olympus AnalySIS image analysis software (ver. 3.2; Soft Imaging System GmbH, Germany). To determine the relative number of FB-positive cells, the neurons were counted in every 16th section in the whole ganglion to avoid double counting (approximately ten sections per animal, per combination studied). The number of cells present on the particular sections as well as the relative frequency of cells exhibiting particular neurochemical phenotype was analyzed by the first author and two other co-authors, blinded to the identity of the antigens studied. At least $560 \mathrm{FB}^{+}$neurons were analyzed for any combination of antigens. Only neurons with clearly visible nucleus (seen as non-immunoreactive "hole" in the middle of the perikaryon) were counted. Data pooled from particular animals groups were expressed as means \pm standard deviation of mean and analyzed with chi-square tests. Statistical significance was inferred at 
Table 1 Specification of immunoreagents

\begin{tabular}{|c|c|c|c|c|}
\hline Antigen & Code & Host species & Dilution & Supplier \\
\hline \multicolumn{5}{|c|}{ Primary antibodies } \\
\hline $\mathrm{CB}$ & CB-38 & Rabbit & $1: 20,000$ & SWANT \\
\hline $\mathrm{TH}$ & MAB 318 & Mouse & $1: 80$ & Chemicon \\
\hline NPY & NZ1115 & Rat & $1: 300$ & Biomol \\
\hline SOM & $8330-0009$ & Rat & $1: 100$ & Biogenesis \\
\hline VIP & $9535-0504$ & Mouse & $1: 2,000$ & Biogenesis \\
\hline NOS & N2280 & Mouse & $1: 2,000$ & Sigma \\
\hline LENK & $4140-0355$ & Mouse & $1: 1,000$ & Biogenesis \\
\hline SP & $8450-0505$ & Rat & $1: 300$ & Biogenesis \\
\hline VAChT & H-V007 & Goat & $1: 2,000$ & Phoenix \\
\hline GAL & T-5036 & Guinea pig & $1: 1,000$ & Peninsula \\
\hline \multicolumn{5}{|c|}{ Secondary reagents } \\
\hline \multicolumn{3}{|c|}{ Donkey anti-mouse $\operatorname{IgG}(\mathrm{H}+\mathrm{L})$ conjugated with FITC } & $1: 800$ & Jackson \\
\hline \multicolumn{3}{|c|}{ Donkey anti-rat $\operatorname{IgG}(\mathrm{H}+\mathrm{L})$ conjugated with FITC } & $1: 800$ & Jackson \\
\hline \multicolumn{3}{|c|}{ Donkey anti-guinea pig IgG $(\mathrm{H}+\mathrm{L})$ conjugated with FITC } & $1: 1,000$ & Jackson \\
\hline \multicolumn{3}{|c|}{ Donkey anti-goat IgG $(\mathrm{H}+\mathrm{L})$ conjugated with FITC } & $1: 1,000$ & Jackson \\
\hline \multicolumn{3}{|c|}{ Biotinylated goat antirabbit immunoglobulins } & $1: 1,000$ & DAKO \\
\hline \multicolumn{3}{|c|}{ Biotin conjugated $\mathrm{F}(\mathrm{ab})$ fragment anti-rabbit $\mathrm{IgG}$} & $1: 1,000$ & BioTrend \\
\hline \multicolumn{3}{|c|}{ CY3-conjugated streptavidin } & $1: 9,000$ & Jackson \\
\hline
\end{tabular}

$* P \leq 0.05, * * P \leq 0.01$, and $* * * P \leq 0.001$ (GraphPad Prism 5: GraphPad Software, La Jolla, CA, USA).

\section{Results}

The control animals contained a large number of retrogradely labeled neurons $\left(\mathrm{FB}^{+}\right)$that were distributed bilaterally, i.e., within both the left and right ganglia. The majority of $\mathrm{FB}^{+}$cells were TH or NPY immunoreactive $(87.8 \pm 4.9$ and $84 \pm 3.1 \%$, respectively) and a large percentage of them co-expressed CB $(36.5 \pm 3.9$ and $28.9 \pm 3.4 \%$, respectively; Table 2 and Figs. 1 and $2 \mathrm{a}-\mathrm{h}$ ). In addition, small subpopulations of $\mathrm{FB}^{+}$neurons coexpressed SOM $(18.7 \pm 2.2 \%)$, VIP $(5.0 \pm 0.9 \%)$, NOS $(1.8 \pm 0.8 \%)$, and LENK $(1.4 \pm 0.8 \%$; Table 2 and Figs. 1, 2i-1, and 3a-1). However, none of the $\mathrm{FB}^{+}$ perikarya were found to be immunopositive to SP, VAChT, and GAL (Table 2). In axotomized animals, the total number of $\mathrm{FB}^{+}$neurons did not change; however, the coding patterns of these cells were profoundly changed. Thus, a strong reduction was observed in the

Table 2 Percentages of retrogradely labeled $\left(\mathrm{FB}^{+}\right)$cells in the porcine interior mesenteric ganglia in control (C) and axotomized (AXO) animals

\begin{tabular}{|c|c|c|c|c|c|c|c|c|}
\hline & \multicolumn{2}{|c|}{$\mathrm{FB}^{+} / \mathrm{CB}^{+} / \mathrm{S}^{+}$} & \multicolumn{2}{|c|}{$\mathrm{FB}^{+} / \mathrm{CB}^{+} / \mathrm{S}^{-}$} & \multicolumn{2}{|c|}{$\mathrm{FB}^{+} / \mathrm{CB}^{-} / \mathrm{S}^{+}$} & \multicolumn{2}{|c|}{$\mathrm{FB}^{+} / \mathrm{CB}^{-} / \mathrm{S}^{-}$} \\
\hline & $\mathrm{C}$ & $\mathrm{AXO}$ & $\mathrm{C}$ & $\mathrm{AXO}$ & $\mathrm{C}$ & $\mathrm{AXO}$ & $\mathrm{C}$ & $\mathrm{AXO}$ \\
\hline TH & $33.4 \pm 4.7$ & $16.8 \pm 3.5$ & $3.1 \pm 1.3$ & $14.5 \pm 3.2$ & $54.4 \pm 5.2$ & $44.2 \pm 3.7$ & $6.9 \pm 1.6$ & $24.4 \pm 3.0$ \\
\hline NPY & $25.1 \pm 3.8$ & $1.4 \pm 0.4$ & $3.8 \pm 0.8$ & $36.0 \pm 1.0$ & $58.9 \pm 2.5$ & $41.6 \pm 1.5$ & $12.2 \pm 2.2$ & $21.0 \pm 2.5$ \\
\hline SOM & $11.1 \pm 1.3$ & $3.4 \pm 0.1$ & $18.7 \pm 2.8$ & $37.2 \pm 8.0$ & $7.6 \pm 3.2$ & $0.3 \pm 0.2$ & $62.3 \pm 1.3$ & $59.1 \pm 8.8$ \\
\hline VIP & $1.5 \pm 1.0$ & 0 & $39.6 \pm 3.5$ & $33.3 \pm 7.1$ & $3.5 \pm 0.9$ & $1.3 \pm 1.3$ & $62.3 \pm 1.3$ & $65.7 \pm 8.0$ \\
\hline NOS & 0 & 0 & $34.7 \pm 4.0$ & $37.5 \pm 7.5$ & $1.8 \pm 0.8$ & 0 & $63.5 \pm 2.7$ & $62.5 \pm 7.5$ \\
\hline LENK & 0 & 0 & $31.9 \pm 1.9$ & $27.3 \pm 6.5$ & $1.4 \pm 0.8$ & $5.8 \pm 1.6$ & $67.0 \pm 2.9$ & $67.2 \pm 0.8$ \\
\hline SP & 0 & 0 & $35.7 \pm 1.5$ & $35.3 \pm 5.6$ & 0 & 0 & $64.5 \pm 2.5$ & $64.7 \pm 5.7$ \\
\hline VAChT & 0 & 0 & $39.3 \pm 1.8$ & $36.3 \pm 6.0$ & 0 & 0 & $62.7 \pm 1.8$ & $63.8 \pm 6.0$ \\
\hline GAL & 0 & 0 & $38.3 \pm 1.8$ & $37.3 \pm 7.0$ & 0 & 0 & $61.7 \pm 1.8$ & $62.8 \pm 7.0$ \\
\hline
\end{tabular}

Data were expressed as mean \pm standard deviation (SD)

$S$ studied substance (NPY, SOM, VIP, etc.) 
Fig. 1 Diagram illustrating the $\mathrm{FB}^{+}$cell numbers which were immunoreactive to appropriate antigens in IMGs of control animals (dark gray bars) and animals with bilateral axotomy of caudal colonic nerves (light gray bars; in percent). Chisquare tests, $* P \leq 0.05, * * P \leq$ $0.01, * * * P \leq 0.001$
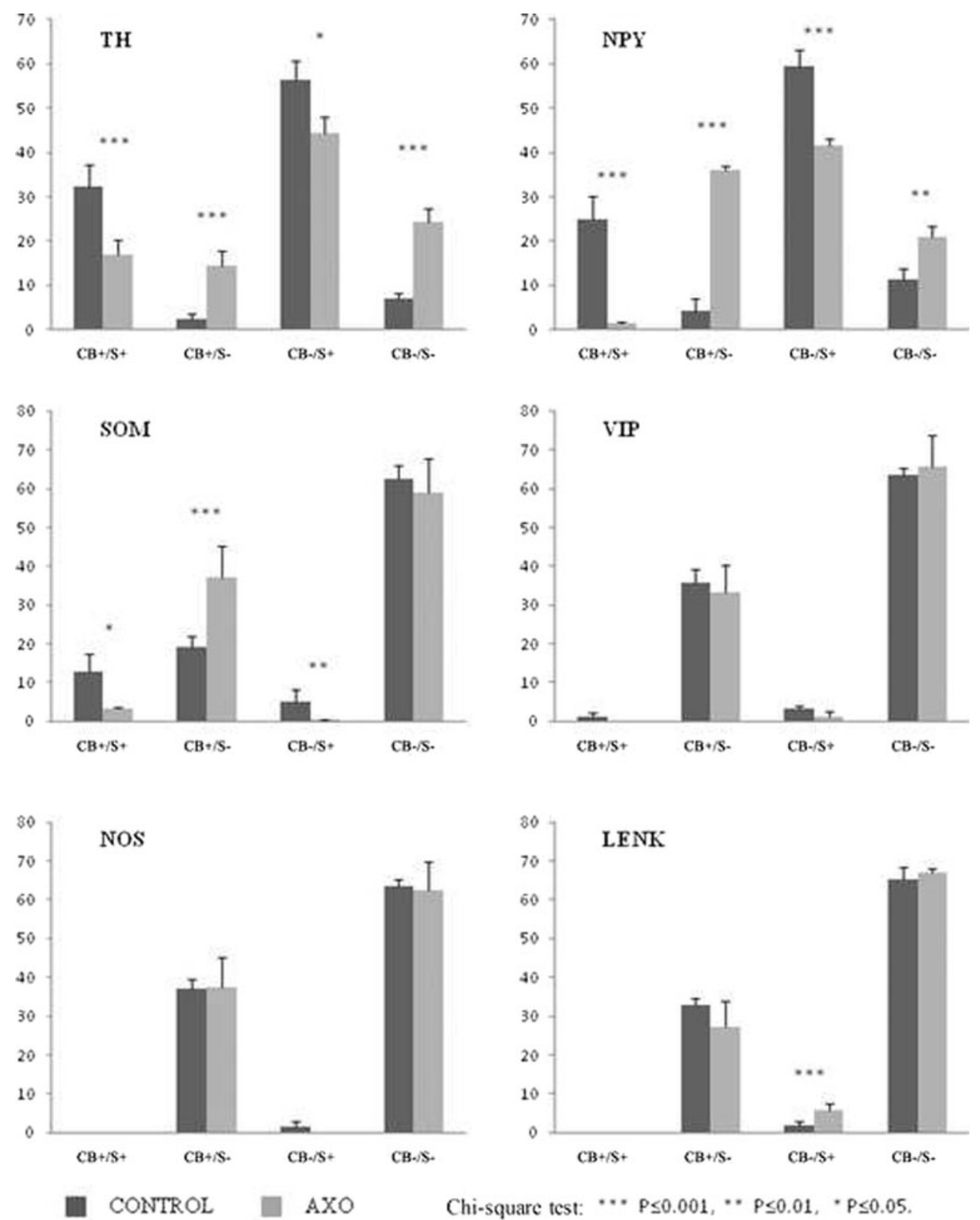
CONTROL AXO Chi-square test: $\cdots p \leq 0.001, \cdots p \leq 0.01, \cdot p \leq 0.05$. number of $\mathrm{FB}^{+} / \mathrm{TH}^{+}(61.0 \pm 3.5$ vs. $87.8 \pm 4.9 \%$, AXO vs. control, respectively; $P \leq 0.001), \mathrm{FB}^{+} / \mathrm{NPY}^{+}(43 \pm 1.0$ vs. $84 \pm 3.1 \%$, AXO vs. control, respectively; $P \leq 0.001)$, and $\mathrm{FB}^{+} / \mathrm{SOM}^{+}(3.7 \pm 0.2$ vs. $18.7 \pm 2.2 \%$, AXO vs. control, respectively; $P \leq 0.001$ ) neurons (Table 2 and Figs. 1 and $\left.2 \mathrm{a}^{\prime}-\mathrm{l}^{\prime}\right)$. Alternatively, the number of $\mathrm{FB}^{+} / \mathrm{VIP}^{+}(P>0.05), \mathrm{FB}^{+} / \mathrm{NOS}^{+}(P>0.05)$, and $\mathrm{FB}^{+} / \mathrm{CB}^{+}(P>0.05)$ neurons was not changed, while the number of $\mathrm{FB}^{+} / \mathrm{LENK}^{+}(5.8 \pm 1.6$ vs. $1.4 \pm 0.8 \%$, AXO vs. control, respectively; $P \leq 0.001)$ cells increased (Table 2 and Figs. 1 and $3 a^{\prime}-1^{\prime}$ ).

It has been found that under physiological conditions $\mathrm{FB}^{+} / \mathrm{CB}^{+}$neurons constituted approximately $35 \%$ of the whole $\mathrm{FB}^{+}$cellular population. It should be stressed that these cells were also neurochemically heterogeneous (Table 2 and Figs. 1 and 2). For example, many of $\mathrm{FB}^{+} / \mathrm{CB}^{+}$cells co-expressed $\mathrm{TH}(33.4 \pm 4.7 \%)$ either NPY $(25.1 \pm 3.8 \%)$ or SOM $(11.1 \pm 1.3 \%)$, while a few of them co-expressed VIP $(1.5 \pm 1.0 \%$; Table 2 and Figs. 1, 2a-h, and $3 \mathrm{a}-\mathrm{d})$. None of the $\mathrm{FB}^{+} / \mathrm{CB}-$ positive perikarya were found to be immunopositive to NOS, LENK, SP, VAChT, and GAL (Table 2 and Figs. 1 and $\left.3 \mathrm{e}^{\prime}-\mathrm{l}^{\prime}\right)$. In axotomized animals, although the total number of the $\mathrm{FB}^{+} / \mathrm{CB}^{+}$cells did not change, a strong reduction was observed among $\mathrm{FB}^{+} / \mathrm{CB}^{+} / \mathrm{TH}^{+}$ (16.8 \pm 3.5 vs. $33.4 \pm 4.7 \%$, AXO vs. control, respectively; $P \leq$ $0.001), \mathrm{FB}^{+} / \mathrm{CB}^{+} / \mathrm{NPY}^{+}(1.4 \pm 0.4$ vs. $25.1 \pm 3.8 \%$, AXO vs. control, respectively; $P \leq 0.001)$, and $\mathrm{FB}^{+} / \mathrm{CB}^{+} / \mathrm{SOM}^{+}(3.4 \pm$ 


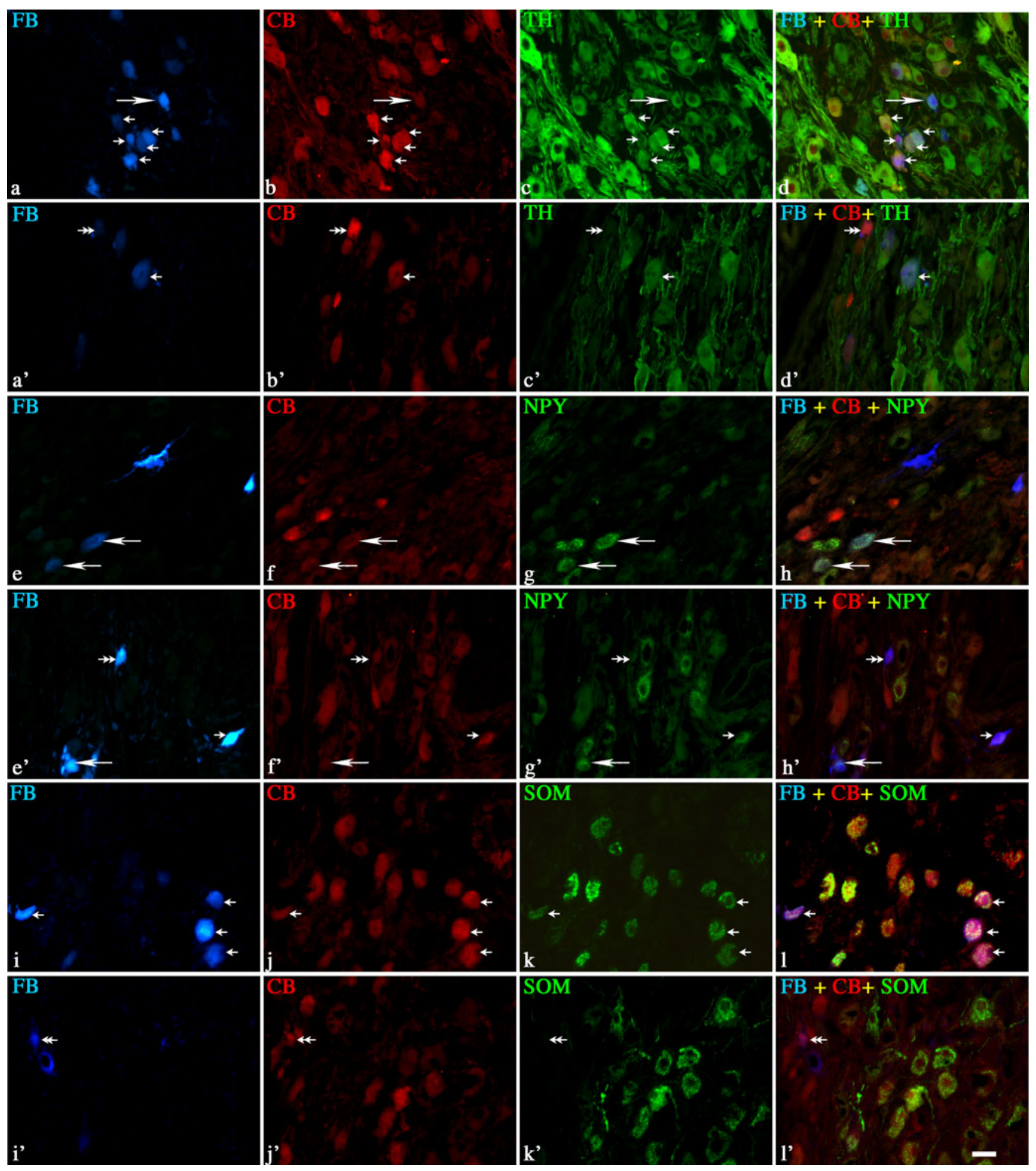

Fig. 2 Representative images of colon-projecting neurons located in IMG of the control animals (C, $a-l)$ and axotomized animals (AXO, $a^{\prime}-$ $\left.l^{\prime}\right) . d, d^{\prime}, h, h^{\prime}, l$, and $l^{\prime}$ are composites of merged images taken separately from blue $\left(a, a^{\prime}, e, e^{\prime}, i, i^{\prime}\right)$, red $\left(b, b^{\prime}, f, f^{\prime}, j, j^{\prime}\right)$, and green $\left(c, c^{\prime}, g, g^{\prime}, k, k^{\prime}\right)$ fluorescent channels. Scale bar in each figure $=50 \mu \mathrm{m} . a-d$ and $a^{\prime}-d^{\prime} \mathrm{FB}^{+} /$ $\mathrm{CB}^{+} / \mathrm{TH}^{+}$neurons in $\mathrm{C}$ and $\mathrm{AXO}$ animals, respectively. The $\mathrm{FB}^{+}(a$ and $a$ ) and $\mathrm{FB}^{+} / \mathrm{CB}^{+} / \mathrm{TH}^{+}\left(d\right.$ and $\left.d^{\prime}\right)$ neurons in $\mathrm{C}$ and $\mathrm{AXO}$ animals, respectively (small arrows). Some $\mathrm{FB}^{+} / \mathrm{TH}^{+}$neurons in $\mathrm{C}$ group were $\mathrm{CB}$ negative (long arrow), $\mathrm{FB}^{+} / \mathrm{CB}^{+} / \mathrm{TH}^{-}$neurons in $\mathrm{AXO}$ animals (small double arrows). $e-h$ and $e^{\prime}-h^{\prime} \mathrm{FB}^{+} / \mathrm{CB}^{+} / \mathrm{NPY}^{+}$neurons in $\mathrm{C}$ and $\mathrm{AXO}$ animals, respectively. Note strong reduction number of $\mathrm{FB}^{+} / \mathrm{CB}^{+} / \mathrm{NPY}^{+}$ ( $h$ and $h^{\prime}$ ) neurons in $\mathrm{AXO}$ animals (small arrow). $\mathrm{FB}^{+} / \mathrm{CB}^{+} / \mathrm{NPY}^{+}$(small arrow), $\mathrm{FB}^{+} / \mathrm{CB}^{+} / \mathrm{NPY}^{-}$(small double arrows), and $\mathrm{FB}^{+} / \mathrm{CB}^{-} / \mathrm{NPY}^{+}$ (long arrows). $i-l$ and $i^{\prime}-l^{\prime} \mathrm{FB}^{+} / \mathrm{CB}^{+} / \mathrm{SOM}^{+}$neurons in $\mathrm{C}$ and $\mathrm{AXO}$ animals, respectively. Note a strong reduction in the number of $\mathrm{SOM}^{+}$ ( $k$ and $k^{\prime}$ ) and $\mathrm{FB}^{+} / \mathrm{CB}^{+} / \mathrm{SOM}^{+}\left(l\right.$ and $\left.l^{\prime}\right)$ neurons in $\mathrm{AXO}$ animals (small arrows). $\mathrm{FB}^{+} / \mathrm{CB}^{+} / \mathrm{SOM}^{+}$(small arrows), $\mathrm{FB}^{+} / \mathrm{CB}^{+} / \mathrm{SOM}^{-}$(small double arrows) 


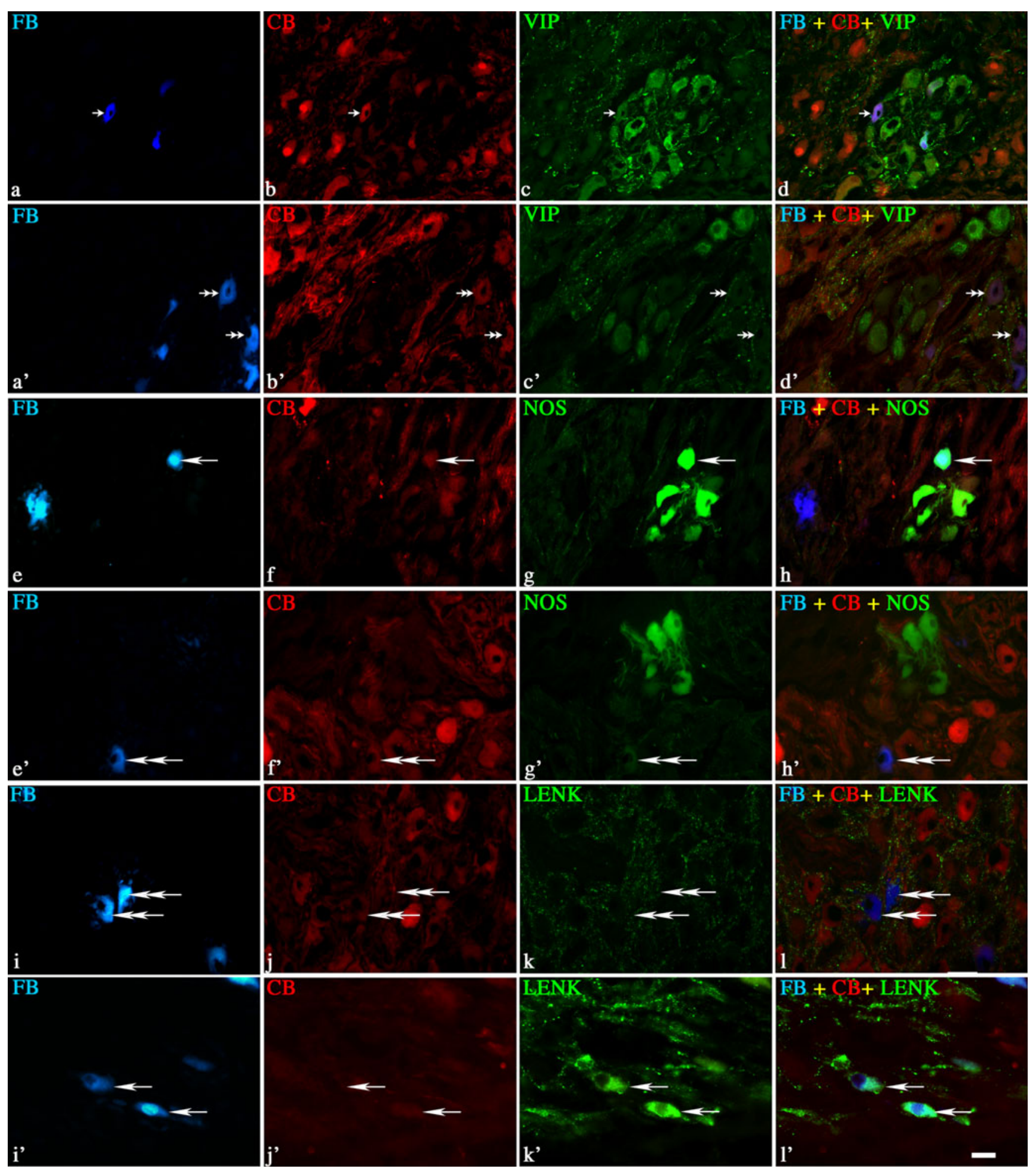

Fig. 3 Representative images of colon-projecting neurons located in IMG of the control animals $(\mathrm{C}, a-l)$ and axotomized animals (AXO, $\left.a^{\prime}-l^{\prime}\right) . d, d^{\prime}, h, h^{\prime}, l$, and $l^{\prime}$ are composites of merged images taken separately from blue $\left(a, a^{\prime}, e, e^{\prime}, i, i^{\prime}\right)$, red $\left(b, b^{\prime}\right.$, $\left.f, f^{\prime}, j, j^{\prime}\right)$, and green $\left(c, c^{\prime}, g, g^{\prime}, k, k^{\prime}\right)$ fluorescent channels. Scale bar in each figure $=50 \mu \mathrm{m} . a-d$ and $a^{\prime}-d^{\prime} \mathrm{FB}^{+} / \mathrm{CB}^{+} / \mathrm{VIP}^{+}$neurons in $\mathrm{C}$ and $\mathrm{AXO}$ animals, respectively. $\mathrm{FB}^{+} / \mathrm{CB}^{+} / \mathrm{VIP}^{+}$(small arrow), $\mathrm{FB}^{+} / \mathrm{CB}^{+} / \mathrm{VIP}^{-}$(small double arrows). $e-h$ and $e^{\prime}-h^{\prime}$ Note the lack of $\mathrm{FB}^{+} / \mathrm{CB}^{+} / \mathrm{NOS}^{+}\left(h\right.$ and $\left.h^{\prime}\right)$ neurons in $\mathrm{C}$ and $\mathrm{AXO}$ animals and strong reduction in the number of $\operatorname{NOS}^{+}\left(g\right.$ and $\left.g^{\prime}\right)$ neurons in $\mathrm{AXO}$ animals. $\mathrm{FB}^{+} / \mathrm{CB}^{+} / \mathrm{NOS}^{-}$(long arrow), $\mathrm{FB}^{+} / \mathrm{CB}^{-} /$ $\mathrm{NOS}^{+}$(long double arrows). $i-l$ and $i^{\prime}-l^{\prime}$ Note the lack of $\mathrm{FB}^{+} /$ $\mathrm{CB}^{+} / \mathrm{LENK}^{+}\left(l\right.$ and $l^{\prime}$ ) neurons in $\mathrm{C}$ and $\mathrm{AXO}$ animals. $\mathrm{FB}^{+} / \mathrm{CB}^{-} /$ $\mathrm{LENK}^{-}$(long double arrows), $\mathrm{FB}^{+} / \mathrm{CB}^{-} / \mathrm{LENK}^{+}$(long arrows) 
0.1 vs. $11.1 \pm 1.3 \%, \mathrm{AXO}$ vs. control, respectively; $P \leq 0.05$ ) neurons (Table 2 and Figs. 1 and $2 a^{\prime}-l^{\prime}$ ).

\section{Discussion}

The pig pattern of axotomy-induced changes in the chemical coding of IMG neurons supplying descending colon The present study demonstrates changes in the chemical coding of the colon-projecting neurons located in the porcine IMG following axotomy of the nervi colici caudales. These changes include a reduction in the number of neurons expressing TH, NPY, and SOM and an increase in the number of neurons immunoreactive to LENK. Although the number of $\mathrm{CB}^{+}$neurons was similar in both the control and axotomized animals, there were significant discrepancies concerning the neurochemical features of this neuronal subset prior and after the injury. Thus, we have observed a strong downregulation of TH, NPY, and SOM expression in $\mathrm{FB}^{+} / \mathrm{CB}^{+}$neurons. Calbindin-D28K plays a major role in calcium homeostasis in neurons and other cell types acting as a fast $\mathrm{Ca}^{2+}$ buffering system in the cytoplasm (Schwaller et al. 2002; Schwaller 2009). This way, calbindin may protect neurons against large fluctuations in free intracellular $\mathrm{Ca}^{2+}$ and prevent cell death. Since axotomy causes a massive influx of calcium into the lesioned neurons (Wolf et al. 2001), an increase in calbindin expression in IMG should be expected. However, it seems not to be the case as the number of CB-expressing neurons was similar in both the control and axotomized animals. One of the possible explanations for such phenomenon in IMG may be that the other calcium-binding proteins like parvalbumin or calretinin were engaged. Such mechanism, for example, i.e., ability to upregulate parvalbumin after axotomy, paralleled by a smaller increase of intracellular calcium was reported in oculomotor neurons of mice (Obal et al. 2006).

The pig pattern of axotomy-induced changes in the IMG vs. other ganglia and/or species It is widely accepted that one of the most relevant changes in the neuronal phenotype following axotomy is the downregulation of physiological neurotransmitter production and the increase in the expression of neuropeptides which are essential for survival and/or regeneration (Hyatt-Sachs et al. 1996; Zigmond and Sun 1997; Zigmond 2000). Our data indicate that the colonprojecting neurons located in the porcine IMG react in a similar manner; however, this manner differs in some details from that described in other ganglia and/or species.

TH The considerable decrease in TH expression in the $\mathrm{FB}^{+}$ population in porcine IMG after caudal colonic nerve axotomy is well in line with earlier data obtained from the porcine IMG after partial or total uterus extirpation (Wasowicz 2003a, b, c). The same phenomenon was also observed in the rat superior cervical ganglia (SCG), where the decreased expression of the catecholamine-producing enzymes has also been noticed after axotomy (Klimaschewski et al. 1996; Shadiack et al. 2001; Sun and Zigmond 1996).

$N P Y$ In addition to the decreased catecholamine production, the axotomy-induced reduction in the number of NPY perikarya was also observed in the porcine IMG, which is consistent with the data obtained from the rat SCG described earlier by Bachoo et al. (1992) and Sun and Zigmond (1996). A decrease of NPY expression should not be surprising since NPY-expressing neurons form a large population among IMG neurons and many of them co-express TH (Pidsudko et al. 2008). Interestingly, after a partial or total uterus extirpation, uterus-projecting IMG neurons expressing NPY were upregulated (Wasowicz 2003a).

SOM SOM is another substance in the present study which was downregulated in neurons of the porcine IMG after axotomy. The reduction of SOM expression in $\mathrm{FB}^{+}$perikarya was surprising since SOM modulates $\mathrm{K}^{+} / \mathrm{Ca}^{2+}$ channel activities that "sensitize" the sympathetic neurons to nerve growth factor and thus can facilitate the neuroregeneration (Patel 1999). Moreover, the induction of SOM production after axotomy has been described previously in the porcine sympathetic chain ganglia (Skobowiat et al. 2011).

VIP and NOS VIP and NOS expressions were not changed in neurons of the porcine IMG after colonic nerve axotomy which is consistent with the previous reports on this subject (Majewski et al. 2002). However, these data run counter to the results of the injury-related responses observed in the neurons of various sympathetic ganglia in rodents, suggesting the existence of either species or target tissue-dependent differences in injury-induced responses (Hyatt-Sachs et al. 1996; Klimaschewski et al. 1996; Shadiack et al. 2001; Sun and Zigmond 1996). For example, it is widely accepted that the axotomy induces or increases the number of neurons expressing VIP and/or NOS in sympathetic ganglia in rodents (HyattSachs et al. 1996; Klimaschewski et al. 1996; Shadiack et al. 2001; Sun and Zigmond 1996). This phenomenon may be attributable to both continuous release of leukemia inhibitory factor from nonneuronal cells at the site of injury (Zigmond 2000) and nerve growth factor deprivation of the affected cells (Shadiack et al. 2001). However, this mechanism does not appear to be involved in the axotomy-driven changes seen in the present study as we did not observed any increase in the number of VIP and/or NOS neurons in the porcine IMG.

LENK Among all IMG neurons studied in the present experiment, only these expressing LENK became more numerous after caudal colonic nerves axotomy. LENK 
overexpression in response to axotomy was already reported in the IMG of the pigs (Majewski et al. 2002). However, axotomy is able to induce increases, but also decreases in the number of LENK expressing cells, depending on the model used (Back and Gorenstein 1994; Linda et al. 1990). Most probably, it is the target tissue that determines the regulation of enkephalins, i.e., target-derived factors either suppress or activate the expression of the leu-enkephalin mRNA precursor normally. Axotomy prevents the target contact, so the target-derived factors cannot act on gene expression anymore.

Summary Our data indicate that the colon-projecting neurons of the porcine IMG react to the axotomy in a similar but not identical manner in a comparison to other species, especially rodents. The existence of species and target tissue-dependent differences in injury-induced responses suggest that further studies are needed to elucidate the detailed factors/mechanisms involved in the response to nerve injury.

Open Access This article is distributed under the terms of the Creative Commons Attribution License which permits any use, distribution, and reproduction in any medium, provided the original author(s) and the source are credited.

\section{References}

Bachoo M, Heppner T, Fiekers J, Polosa C (1992) A role for protein kinase $\mathrm{C}$ in long term potentiation of nicotinic transmission in the superior cervical ganglion of the rat. Brain Res 585:299-302

Back SA, Gorenstein C (1994) Differential response of neutral endopeptidase 24.11 ("enkephalinase"), and cholinergic and opioidergic markers to hypoglossal axotomy. J Comp Neurol 340:149-160

Balemba OB, Grondahl ML, Mbassa GK, Semuguruka WD, HaySmith A, Skadhauge E, Dantzer V (1998) The organisation of the enteric nervous system in the submucous and mucous layers of the small intestine of the pig studied by VIP and neurofilament protein immunohistochemistry. J Anat 192(Pt 2):257-267

Boeshore KL, Schreiber RC, Vaccariello SA, Sachs HH, Salazar R, Lee J, Ratan RR, Leahy P, Zigmond RE (2004) Novel changes in gene expression following axotomy of a sympathetic ganglion: a microarray analysis. J Neurobiol 59:216-235

Brown DR, Timmermans JP (2004) Lessons from the porcine enteric nervous system. Neurogastroenterol Motil 16:50-54

Dalsgaard CJ, Elfvin LG (1982) Structural studies on the connectivity of the inferior mesenteric ganglion of the guinea pig. J Auton Nerv Syst 5:265-278

Ekblad E, Sjuve R, Arner A, Sundler F (1998) Enteric neuronal plasticity and a reduced number of interstitial cells of Cajal in hypertrophic rat ileum. Gut 42:836-844

Furness JB (2012) The enteric nervous system and neurogastroenterology. Nat Rev Gastroenterol Hepatol 9:286-294

Gonkowski S, Calka J (2010) Changes in the somatostatin (SOM)-like immunoreactivity within nervous structures of the porcine descending colon under various pathological factors. Exp Mol Pathol 88:416-423
Gonkowski S, Calka J (2012) Changes in pituitary adenylate cyclaseactivating peptide 27-like immunoreactive nervous structures in the porcine descending colon during selected pathological processes. J Mol Neurosci 48:777-787

Hyatt-Sachs H, Bachoo M, Schreiber R, Vaccariello SA, Zigmond RE (1996) Chemical sympathectomy and postganglionic nerve transection produce similar increases in galanin and VIP mRNA but differ in their effects on peptide content. J Neurobiol 30:543-555

Klimaschewski L, Kummer W, Heym C (1996) Localization, regulation and functions of neurotransmitters and neuromodulators in cervical sympathetic ganglia. Microsc Res Tech 35:44-68

Klimaschewski L, Tran TD, Nobiling R, Heym C (1994) Plasticity of postganglionic sympathetic neurons in the rat superior cervical ganglion after axotomy. Microsc Res Tech 29:120-130

Koszykowska M, Calka J, Ganko M, Jana B (2011) Long-term estradiol-17beta administration reduces population of neurons in the sympathetic chain ganglia supplying the ovary in adult gilts. Exp Mol Pathol 91:353-361

Krebs C, Neiss WF, Streppel M, Guntinas-Lichius O, Dassesse D, Stennert E, Pochet R (1997) Axotomy induces transient calbindin D28K immunoreactivity in hypoglossal motoneurons in vivo. Cell Calcium 22:367-372

Li MZ, Masuko S (2001) Target specific organization and neuron types of the dog pelvic ganglia: a retrograde-tracing and immunohistochemical study. Arch Histol Cytol 64:267-280

Linda H, Cullheim S, Risling M, Arvidsson U, Mossberg K, Ulfhake B, Terenius L, Hokfelt T (1990) Enkephalin-like immunoreactivity levels increase in the motor nucleus after an intramedullar axotomy of motoneurons in the adult cat spinal cord. Brain Res 534:352-356

Lindh B, Risling M, Remahl S, Terenius L, Hokfelt T (1993) Peptideimmunoreactive neurons and nerve fibres in lumbosacral sympathetic ganglia: selective elimination of a pathway-specific expression of immunoreactivities following sciatic nerve resection in kittens. Neuroscience 55:545-562

Litten-Brown JC, Corson AM, Clarke L (2010) Porcine models for the metabolic syndrome, digestive and bone disorders: a general overview. Animal 4:899-920

LoPachin RM, Lehning EJ (1997) Mechanism of calcium entry during axon injury and degeneration. Toxicol Appl Pharmacol 143:233244

Luckensmeyer GB, Keast JR (1995) Distribution and morphological characterization of viscerofugal projections from the large intestine to the inferior mesenteric and pelvic ganglia of the male rat. Neuroscience 66:663-671

Majewski M, Bossowska A, Gonkowski S, Wojtkiewicz J, Brouns I, Scheuermann DW, Adriaensen D, Timmermans JP (2002) Neither axotomy nor target-tissue inflammation changes the NOS- or VIP-synthesis rate in distal bowel-projecting neurons of the porcine inferior mesenteric ganglion (IMG). Folia Histochem Cytobiol 40:151-152

Mohney RP, Siegel RE, Zigmond RE (1994) Galanin and vasoactive intestinal peptide messenger RNAs increase following axotomy of adult sympathetic neurons. J Neurobiol 25:108-118

Obal I, Engelhardt JI, Siklos L (2006) Axotomy induces contrasting changes in calcium and calcium-binding proteins in oculomotor and hypoglossal nuclei of Balb/c mice. J Comp Neurol 499:17-32

Olsson C, Chen BN, Jones S, Chataway TK, Costa M, Brookes SJ (2006) Comparison of extrinsic efferent innervation of guinea pig distal colon and rectum. J Comp Neurol 496:787-801

Patel YC (1999) Somatostatin and its receptor family. Front Neuroendocrinol 20:157-198

Patterson JK, Lei XG, Miller DD (2008) The pig as an experimental model for elucidating the mechanisms governing dietary influence on mineral absorption. Exp Biol Med (Maywood) 233:651-664

Phillips RJ, Powley TL (2007) Innervation of the gastrointestinal tract: patterns of aging. Auton Neurosci 136:1-19 
Pidsudko Z, Kaleczyc J, Wasowicz K, Sienkiewicz W, Majewski M, Zajac W, Lakomy M (2008) Distribution and chemical coding of intramural neurons in the porcine ileum during proliferative enteropathy. J Comp Pathol 138:23-31

Purves-Tyson TD, Keast JR (2004) Rapid actions of estradiol on cyclic amp response-element binding protein phosphorylation in dorsal root ganglion neurons. Neuroscience 129:629-637

Reimer M, Kanje M (1999) Peripheral but not central axotomy promotes axonal outgrowth and induces alterations in neuropeptide synthesis in the nodose ganglion of the rat. Eur $\mathrm{J}$ Neurosci 11:3415-3423

Schwaller B (2009) The continuing disappearance of "pure" $\mathrm{Ca}^{2+}$ buffers. Cell Mol Life Sci 66:275-300

Schwaller B, Meyer M, Schiffmann S (2002) 'New' functions for 'old' proteins: the role of the calcium-binding proteins calbindin D$28 \mathrm{k}$, calretinin and parvalbumin, in cerebellar physiology. Studies with knockout mice. Cerebellum 1:241-258

Shadiack AM, Sun Y, Zigmond RE (2001) Nerve growth factor antiserum induces axotomy-like changes in neuropeptide expression in intact sympathetic and sensory neurons. J Neurosci 21:363-371

Skobowiat C, Calka J, Majewski M (2011) Axotomy induced changes in neuronal plasticity of sympathetic chain ganglia ( $\mathrm{SChG}$ ) neurons supplying descending colon in the pig. Exp Mol Pathol 90:13-18

Sullivan TP, Eaglstein WH, Davis SC, Mertz P (2001) The pig as a model for human wound healing. Wound Repair Regen 9:66-76

Sun Y, Landis SC, Zigmond RE (1996) Signals triggering the induction of leukemia inhibitory factor in sympathetic superior cervical ganglia and their nerve trunks after axonal injury. Mol Cell Neurosci 7:152-163

Sun Y, Zigmond RE (1996) Involvement of leukemia inhibitory factor in the increases in galanin and vasoactive intestinal peptide mRNA and the decreases in neuropeptide $\mathrm{Y}$ and tyrosine hydroxylase mRNA in sympathetic neurons after axotomy. J Neurochem 67:1751-1760
Swindle MM, Makin A, Herron AJ, Clubb FJ Jr, Frazier KS (2012) Swine as models in biomedical research and toxicology testing. Vet Pathol 49:344-356

Swindle MM, Smith AC (2007) Swine in biomedical research. In: Conn PM (ed) Sourcebook of models for biomedical research. Human, Totowa

Verma N, Rettenmeier AW, Schmitz-Spanke S (2011) Recent advances in the use of Sus scrofa (pig) as a model system for proteomic studies. Proteomics 11:776-793

Wasowicz K (2003a) Effect of total or partial uterus extirpation on sympathetic uterus-projecting neurons in porcine inferior mesenteric ganglion. B. Changes in expression of neuropeptide Y, galanin, vasoactive intestinal polypeptide, pituitary adenylate-cyclase activating peptide, somatostatin and substance P. Pol J Vet Sci 6:147-160

Wasowicz K (2003b) Effect of total or partial uterus extirpation on uterus-projecting neurons in porcine inferior mesenteric ganglion. A. Changes in expression of transmitter-synthesizing enzymestyrosine hydroxylase, dopamine beta-hydroxylase and choline acetyltransferase. Pol J Vet Sci 6:131-145

Wasowicz K (2003c) Effect of total or partial uterus extirpation on uterusprojecting neurons in porcine inferior mesenteric ganglion. C. Changes in expression of apoptosis-associated (Bcl-2 and Bax) and regeneration-associated (GAP-43) proteins. Pol J Vet Sci 6:161-172

Wolf JA, Stys PK, Lusardi T, Meaney D, Smith DH (2001) Traumatic axonal injury induces calcium influx modulated by tetrodotoxinsensitive sodium channels. J Neurosci 21:1923-1930

Yamada J, Hayashi Y, Jinno S, Wu Z, Inoue K, Kohsaka S, Nakanishi $\mathrm{H}$ (2008) Reduced synaptic activity precedes synaptic stripping in vagal motoneurons after axotomy. Glia 56:1448-1462

Zigmond RE (1997) LIF, NGF and cell body response to axotomy. Neuroscientist 3185

Zigmond RE (2000) Neuropeptide action in sympathetic ganglia. Evidence for distinct functions in intact and axotomized ganglia. Ann N Y Acad Sci 921:103-108

Zigmond RE, Sun Y (1997) Regulation of neuropeptide expression in sympathetic neurons. Paracrine and retrograde influences. Ann N Y Acad Sci 814:181-197 